\title{
A abordagem da morte na formaçáo de profissionais e acadêmicos da enfermagem, medicina e terapia ocupacional $^{1}$
}

\author{
Aline Viegas Sartori, Amara Lúcia Holanda Tavares Battistel \\ Universidade Federal de Santa Maria - UFSM, Santa Maria, RS, Brasil.
}

\begin{abstract}
Resumo: Objetivo: Este artigo decorreu de uma investigação sobre o significado da morte no cotidiano dos profissionais e acadêmicos da terapia ocupacional, medicina e enfermagem. Método: Discorre sobre dois eixos investigativos, que abordaram o significado da morte e o papel da formação acadêmica quanto ao preparo para lidar com a terminalidade da vida. Trata-se de uma pesquisa de abordagem qualitativa baseada nos pressupostos da investigação fenomenológica. Os dados foram coletados por meio de entrevista narrativa, norteada por uma matriz categorial e interpretados por meio da análise textual discursiva. Foram investigados três profissionais, residentes e acadêmicos de cada categoria profissional. Resultados: Os resultados mostraram que, embora a morte seja um fenômeno natural e inevitável da existência humana, tende a ser negado socialmente. Muitas pessoas buscam suporte na religião e espiritualidade. No que se refere à abordagem da morte na formação acadêmica, os dados evidenciaram a prioridade em relação ao cuidado e atenção à saúde e à vida. A população investigada aprendeu a conviver com a questão por meio de suas experiências pessoais de vida e de profissão, tanto no período de formação acadêmica quanto no exercício da profissão. Conclusão: O estudo contribuiu para ampliar a discussão sobre a importância do suporte à formação dos profissionais da saúde tanto no que se refere à aprendizagem da assistência voltada aos cuidados paliativos, quanto à necessidade de instrumentalizá-los e fortalecê-los em relação ao impacto que a morte exerce em seu cotidiano.
\end{abstract}

Palavras-chave: Morte, Cuidados Paliativos, Formação de Recursos Humanos, Profissionais da Saúde, Terapia Ocupacional.

\section{Approaching death in the training of nursing, medicine and occupational therapy professionals}

\begin{abstract}
Objective: This work is part of a research that investigated the meaning of death in the daily routine of occupational therapy, medicine and nursing students and professionals. Method: Two investigative methods were used, approaching the meaning of death and its role in the academic training as a preparation for dealing with the theme. The study has qualitative approach and is based on assumptions of phenomenological research. Data was collected through a narrative interview guided by a categorical matrix and interpreted by means of a discursive textual analysis. Nine individuals were investigated, including professionals, residents and academic students from each area. Results: The results revealed that, although death is seen as a natural and inevitable phenomenon of human existence, it has been systematically denied by society. Many people find support in religion and spirituality. Regarding the role of death in the academic training, the data clearly showed that academy prioritizes the care and attention to health and life and it does not teach to deal with death nor prepares professionals to act in the logic of palliative care. The people investigated in this research learned to deal with death from personal and work
\end{abstract}

Autor para correspondência: Aline Viegas Sartori, Departamento de Fisioterapia e Reabilitação, Universidade Federal de Santa Maria, Av. Roraima, Prédio 26, Camobi, CEP 97105-900, Santa Maria, RS, Brasil, e-mail: alinevsartori15@gmail.com 
experiences. Conclusion: This study contributed to expand the discussion about the importance of support to the training of health professionals, both in terms of learning about assistance focused on palliative care, and of the need to instruct and strengthen them before the impact that death causes in their daily lives.

Keywords: Death, Palliative Care, Staff Development, Health Professionals, Occupational Therapy.

\section{Introdução}

A morte é um fenômeno que pode ter múltiplas interpretaçóes. Devido ao fato de ser sinônimo de perda, sofrimento e dor, é muito comum ocorrer uma visão negativa sobre ela, bem como o medo de seu enfrentamento, embora seja a única certeza da vida e um fenômeno que ocorrerá cedo ou tarde para todos os seres vivos. Autores como Moritz (2005) e Kübler-Ross (2008) descrevem a interpretação da morte como um castigo, uma ação má, que gera desconforto diante da ideia de imprevisibilidade e inevitabilidade que ela sugere, e que promove uma separação e perda das experiências vivenciadas. Nesse contexto é comum a fuga do tema para evitar o confronto com a dura realidade. Entretanto, a fuga sobrevém até que o indivíduo se confronte com a morte do próximo, diante disso, se faz necessário reconstruir uma nova relação com o mundo em que se vive. Nesse cenário, de alguma forma é experimentada a morte dentro de si.

Essa compreensão sobre a morte é alimentada pela forma como o tema é tratado na cultura ocidental. Desde cedo as pessoas associam a ideia de morte a algo desagradável. As crianças são inibidas da vivência da morte e do processo de luto, em uma tentativa de proteçáo ao sofrimento, de modo que se fala o menos possível sobre o tema e quando o fazem é por meio de eufemismos, como forma de manter a morte distante da realidade (TORRES, 1979; CARVALHO, 1994 apud ARAÚJO, 2006). As pessoas são despreparadas pela vida para falar sobre o assunto com naturalidade, principalmente quando se trata da própria finitude. Assim, constrói-se uma visão social que faz a morte representar o desconhecido e ser rejeitada pela grande maioria das pessoas. Para Kübler-Ross (2008), de forma inconsciente, o homem lida com a própria morte como um evento impossível de ocorrer, e esta ideação dificulta a aceitação de que a morte aconteça para si.

Rodrigues (2006) e Kübler-Ross (2008) revelam que a despeito da morte ser rejeitada, não se pode negar a sua existência. Resta, então, a tentativa de dominá-la. Como resultado dessa concepção, “[...] controlar a morte transformou-se em finalidade científica, sobretudo em decorrência dos avanços técnico-científicos observados nas últimas décadas
[...]" (SILVA et al., 2012, p. 444). A morte passa a ser tratada como um evento não natural da vida e que, portanto, deve ser veementemente evitada. Nessa perspectiva, o tratamento que se conduz ao paciente sem recursos de cura é a busca de possibilidades ou avanços da ciência a fim de descobrir uma cura milagrosa. Esse procedimento frequentemente leva o paciente a um prolongamento de vida, náo raro em um processo sofrido para ele e para os familiares.

A submissão a procedimentos e tratamentos excessivos e fúteis, para além do que o paciente poderia ter escolhido, é definida pela Academia Nacional de Cuidados Paliativos - ANCP (MACIEL et al., 2006, p. 12) como "futilidade terapêutica" ou "tratamento fútil", que se resume a:

[...] medida cuja adoção pode prolongar o sofrimento e mesmo a morte, não sendo efetiva para corrigir ou melhorar as condições que ameaçam a vida. São procedimentos diagnósticos ou terapêuticos inadequados e inúteis diante da situação evolutiva e irreversível da doença e que podem causar sofrimento acrescido ao doente e à família.

Nesse sentido, Moritz e Nassar (2004) afirmam a necessidade de reconhecer o tratamento como fútil e levar essa informação ao conhecimento da família e do paciente a fim de preservar a autonomia dos envolvidos nas decisóes sobre o tratamento até os últimos instantes.

Embora essa luta contra a morte indique um grande avanço tecnológico, fica o questionamento quanto à qualidade de vida nos últimos instantes e em que a sobrevivência a qualquer custo pode ser considerada vida. A tecnologia ajuda a prolongar a existência dos doentes, porém não os ajuda a vivenciar o processo de morrer de forma qualificada. Nesse sentido, Costa e Lima (2005) afirmam que o paciente sem possibilidades de cura ainda é visto como alguém passivo que não tem papel funcional nem direito a fazer escolhas. Nessa perspectiva, Araújo (2006) e Kübler-Ross (2008) referem que o sujeito perde a autonomia frente aos procedimentos hospitalares e à sua doença. $\mathrm{O}$ controle de sua vida passa a ser de seus familiares e dos profissionais da saúde, que lutam pela cura do paciente. Os profissionais da saúde assumem grandes responsabilidades perante pacientes com quadros graves. Em busca de saúde, 
eles tentam todos os procedimentos possíveis que possam levar a algum resultado positivo, mesmo quando têm a clareza de que seria necessário um milagre para que a cura viesse a ocorrer.

Essa prática evidencia a visão da impotência na luta contra a morte, e dela decorre o modelo de formação acadêmica dos profissionais da saúde, os quais são preparados para atuar frente à vida, sem considerar o enfrentamento da morte como uma atribuição para a qual o profissional também precisa estar apto. Bifulco e Iochida (2009) referem que uma das causas da inaptidão dos profissionais para lidar com a morte é a crença de que, para formar bons profissionais, é necessário dar ênfase aos aspectos técnico-científicos em detrimento dos aspectos emocionais, espirituais e sociais do ser humano.

$\mathrm{O}$ reconhecimento da fragilidade na atenção à saúde dos pacientes sem possibilidades de cura, da compreensão da importância do manejo adequado a estes pacientes, bem como da necessidade de oferecer suporte técnico e emocional aos profissionais que atuam com a terminalidade da vida, fez surgir uma forma mais humana de trabalhar nesse contexto. Surgiu, assim, a tecnologia de atenção à saúde denominada cuidados paliativos.

A ANCP conceitua os cuidados paliativos como os cuidados que se prestam ao paciente que está fora das possibilidades de cura e têm como componentes principais o alívio dos sintomas e o apoio psicológico, espiritual, emocional e social durante todo o acompanhamento do paciente até após sua morte, bem como durante o período de luto de sua família, caracterizando-se um acompanhamento interdisciplinar (MACIEL et al., 2006).

A equipe básica para os cuidados paliativos, conforme a ANCP, inclui médico(a), enfermeiro(a), assistente social, psicólogo(a), fisioterapeuta, terapeuta ocupacional, voluntários e assistentes espirituais que devem estar adequadamente habilitados em relação aos princípios dos cuidados paliativos (MACIEL et al., 2006). Esta equipe é preparada para lidar com os aspectos mais delicados que envolvem o paciente e a família no momento em que, geralmente, a maioria das pessoas busca fugir - a hora da morte. Por isso é de suma importância a existência de profissionais habilitados e com formaçáo em cuidados paliativos no quadro dos trabalhadores da saúde dos hospitais e serviços que lidam com a morte. É consenso entre os pesquisadores da área (DE CARLO et al., 2005; DE CARLO; QUEIROZ, 2007; FERRER; SANTOS, 2007; OTHERO; COSTA, 2007; TAKEDA, 2009; SEKI; GALHEIGO, 2010; QUEIROZ, 2012) que os serviços de cuidados paliativos são essenciais em locais em que a possibilidade de morte se faz presente.
Estas questóes que perpassaram as atividades desenvolvidas no projeto de pesquisa e extensão $\mathrm{CAACTO}^{2}$ e no estágio supervisionado em Terapia Ocupacional na Oncologia Infanto-juvenil/UFSM levaram a reflexóes sobre o significado da morte no cotidiano de profissionais, pacientes e seus familiares. Destas vivências decorreu a inquietação quanto à formação e ao preparo dos profissionais da saúde para lidar com o tema e culminou com o Trabalho de Conclusão do $\mathrm{Curso}^{3}$, do qual resultou este artigo. Nele são apresentados os resultados parciais da pesquisa cujos dados coletados foram categorizados em quatro eixos norteadores, quais sejam: a "Concepção de morte", "Formação acadêmica", "Impacto no cotidiano" e "Atitude frente à morte". Neste trabalho foram abordados apenas os dois primeiros eixos. O primeiro discutiu a concepção e o significado da morte para os profissionais da saúde das áreas já mencionadas e o segundo eixo abordou a formação dos profissionais e acadêmicos da área da saúde, assim como as estratégias que amparam o estudante e futuro profissional para lidar com a terminalidade da vida.

\section{Método}

Para responder aos objetivos da pesquisa, adotou-se a abordagem qualitativa do tipo Investigação Narrativa, baseada nos pressupostos da pesquisa fenomenológica (CONNELLY; CLANDININ, 1995). A metodologia qualitativa permite que se empregue a perspectiva da análise fenomenológica no processo investigativo, pois este consiste em observar a interpretação de ideias que o indivíduo forma em sua consciência com base nas experiências vividas; procura-se, por meio dela, entender melhor as situaçóes vivenciadas (GIL, 2010).

Para compreender a concepção que os profissionais e acadêmicos da saúde têm frente à morte de seus pacientes, foram entrevistados um profissional, um residente e um acadêmico de cada uma das áreas da enfermagem, da medicina e da terapia ocupacional, totalizando nove participantes. Como critério de inclusão, os entrevistados deveriam atuar ou ter atuado no CTCriaC do HUSM, ter alguma vivência relacionada à morte de seus pacientes e que aceitassem participar voluntariamente da pesquisa.

Tendo em vista o número reduzido da equipe, a amostra foi selecionada de modo a contemplar de forma equilibrada os profissionais das áreas selecionadas. Considerando que esta pesquisa foi realizada para a elaboração de um trabalho de conclusão de curso, e tendo em vista a exiguidade do tempo para sua realização, foi necessário restringir o número de áreas 
e de participantes a serem investigados. Por igual motivo, este estudo se limitou a um único serviço. Espera-se no futuro poder expandir a pesquisa a serviços que prestem atendimentos semelhantes.

O critério de escolha das áreas dos participantes investigados se deu pelo fato de a área de formação da pesquisadora ser a terapia ocupacional e por serem os profissionais da medicina e da enfermagem quem, no serviço investigado, se envolvem mais diretamente com a comunicação da má notícia e com os encaminhamentos relativos aos procedimentos relacionados ao óbito.

Os dados foram coletados entre os meses de maio e junho de 2013, pela própria pesquisadora, a qual estava inserida no serviço desde 2009, por meio da participação em projetos de extensão e prática de estágio. Foi preenchida uma ficha com o perfil sociodemográfico dos profissionais investigados e realizadas entrevistas individuais, tendo como guia uma Matriz Categorial. As entrevistas foram gravadas em áudio para posterior transcrição e organização das categorias emergentes. Também foi realizada uma busca nas grades curriculares dos cursos envolvidos a fim de identificar a oferta de disciplinas que poderiam abordar o assunto.

A análise dos dados foi realizada por meio da Análise Textual Discursiva (MORAES; GALIAZZI, 2007). Os entrevistados estáo representados por uma letra do alfabeto e um número: a letra indica a categoria profissional - Profissionais (P), Residentes (R) e Acadêmicos (A) - e os números 1, 2 e 3 representam a formação inicial em enfermagem, medicina e terapia ocupacional, respectivamente.

\section{Resultados e Discussão}

Os dados obtidos nas fichas sociodemográficas mostraram que, dos nove participantes da pesquisa, oito são do gênero feminino, com a faixa etária entre 21 a 58 anos de idade, distribuídos da seguinte forma entre as categorias: os acadêmicos apresentaram idade entre 21 a 24 anos, todos com mais de um ano e meio de atuação no setor por meio de estágios e projetos; os residentes apresentaram faixa etária entre 23 a 32 anos, com um ano e meio a três anos de atuação no serviço. Os profissionais, por sua vez, apresentaram idade entre 27 a 58 anos, dois com 5 anos e um com 35 anos de atuação. Cabe acrescentar que, destes participantes, apenas cinco (três acadêmicos, um residente e um profissional) têm formaçáo inicial realizada na UFSM.

Seguem-se os dados relativos aos eixos norteadores da pesquisa, iniciando com aquele referente à concepção da morte pelos participantes investigados.

\subsection{A concepção de morte}

Baseado na hipótese levantada por Kübler-Ross (2008) de que a morte na sociedade contemporânea é inconcebível inconscientemente, buscou-se compreender, no eixo "Concepção da morte", o significado de morte para os participantes da pesquisa a partir de sua experiência de vida e de profissão. Foi possível perceber que há duas principais formas de tentar explicar a morte: como processo de natureza biológica (encerramento do ciclo da vida) ou como processo de natureza espiritual (baseado na religião e na espiritualidade).

A concepção de morte como processo natural e biológico foi observada nos discursos dos entrevistados das categorias profissional e acadêmico. Em suas narrativas apareceu a naturalidade com que se lida com a morte, vista como um acontecimento inevitável e que faz parte de um ciclo natural da vida. Como pode ser verificado pelos excertos abaixo, dos participantes categorizados como Profissionais:

A morte pra mim é uma coisa certa, eu enfrento ela com muita naturalidade. Ela faz parte da minha vida, porque quando eu nasci eu já estava programada pra um dia morrer (P1).

É um processo de encerramento de um ciclo (P3).

Pra medicina a morte de um paciente a gente vê como consequência de uma doença, consequência de alguma coisa que aconteceu de uma maneira bem prática assim (P2).

É uma etapa da nossa evolução de vida. A gente nasce, cresce, se desenvolve e em algum momento a gente vai morrer por um ou outro motivo. Então, é uma coisa obrigatória, que vai acontecer com todo mundo. Mais ou menos traumática para alguma ou outra pessoa e para as pessoas que cercam, mas é uma coisa inevitável (P2).

A mesma concepção também foi partilhada pelos acadêmicos investigados.

Tu sabes que é natural, tu vais nascer, crescer e morrer (A3).

Pra mim a morte é uma coisa tão natural como o nascimento, sabe? É o momento que realmente a pessoa não tem mais condiçốes tanto físicas, como fisiológicas de continuar (A1).

É uma coisa natural da vida, que isso vai acontecer com todo mundo (A2).

Os achados da pesquisa correspondem ao que Araújo (2006) propôs quando referiu que a lógica natural e biológica do homem é nascer, crescer, tornar-se adulto, reproduzir-se, envelhecer e morrer. 
Embora a morte seja parte da vida, quando ocorre mais cedo do que se espera, como é o caso do contexto em que a pesquisa foi realizada, aceitá-la é muito difícil e muitas vezes incompreensível. E a antiga referência da morte como parte da vida ganha outro contorno, até porque a morte na infância foge da expectativa do ciclo vital, como se pode perceber no excerto a seguir:

Quando isso [a morte] acontece na infância, a parte do crescer é muito abreviada, então é muito mais dificil de compreender e dai a gente começa a questionar, mas porque tão jovem? (A3).

A morte na sociedade, de maneira geral, é negada. Conforme Kübler-Ross (2008), é difícil encarar a morte como um fenômeno natural, normalmente ela vem atribuída a aspectos negativos e malignos. De acordo com Branco (2003, p.77), com o avanço da tecnologia, criou-se um mito: "[...] o de que a ciência é capaz, por si só, de resolver todos os problemas existentes em relação à saúde da pessoa". Com esse pensamento, se nega a morte como uma realidade, temendo que ela aconteça, e se coloca nas mãos do médico e outros profissionais o seu controle e a busca de uma cura. Quando profissionais de saúde entram em práticas hospitalares, a morte começa a fazer parte do cotidiano, sendo necessário desmistificar essa negação e elaborar reflexões sobre o assunto, como é possível observar nesse trecho da narrativa de P3:

Estar nesse espaço do hospital faz com que a gente fique o tempo inteiro sendo recordado, de que a morte é algo que está muito próximo e que pra isso a gente precisa está se preparando para esse processo, que pode vir acontecer a qualquer momento (P3).

Mesmo com essa visão, Kovács (2010, p. 150) faz uma observação de que as instituiçóes hospitalares acabam promovendo uma "assepsia emocional" para que o contágio do sofrimento seja evitado. Assim, a morte continua sendo de certa forma negada, por ser um assunto difícil de lidar com os pacientes, principalmente quando não se tem preparaçáo para isso.

O participante $\mathrm{P} 3$ trouxe também em sua narrativa esta afirmação:

A morte no hospital é uma morte anunciada e é uma morte muito próxima. A luta pela vida fica mais evidenciada (P3).

Essa ideia corrobora com o que Ariès (1977 apud KOVÁCS, 1992) tenta explicar em seus estudos quanto às transformaçóes sociais que a compreensão da morte sofreu ao passar dos séculos.
O que antigamente era visto como um ato público e melhor compreendido, hoje é um tema visto como vergonhoso, que se esconde e sobre o qual se receia falar. A morte deixou de acontecer no próprio lar do sujeito e passou a ocorrer nos leitos de hospitais, com o paciente isolado do mundo externo, distante dos entes queridos e na busca de uma cura por meio da esperança que se deposita na ciência e na religião.

Por outro lado, a concepção de a morte relacionada a uma crença religiosa e à espiritualidade está fundamentada no fato de que "[...] o ser humano não está preparado para aceitar a imposição de que seu destino é morrer e prefere acreditar que a morte é o começo de uma nova vida infinita [...]" (ARAÚJO, 2006, p. 23). Como pode ser observado nos relatos dos participantes de todas as categorias, na maioria das entrevistas há uma referência à religiáo mostrando que ela tem um papel importante de conduzir alguns pensamentos e confortar de alguma forma o enfrentamento de situaçóes que envolvem a morte e o morrer. As narrativas a seguir explicitam essa compreensáo: "Eu acredito que a maioria das pessoas que, por exemplo, tem uma religiáo, alguma crença, tem uma maior facilidade de lidar com isso" (A3) ou "Eu acho que isso também depende muito no que a gente crê, no que a gente pensa, se existe algo depois [da morte], se não existe" (A2) e ainda "hoje pra mim a morte é um estado de conforto” (R3).

Conforme Bromberg (1994 apud ARAÚJO, 2006) e Kovács (1991 apud BRÊTAS; OLIVEIRA; YAMAGUTI, 2006), a morte pode ser interpretada como um processo de transição entre mundos, uma transição espiritual que revela crenças que confortam o homem. Esse suporte encontrado, muitas vezes, coloca a morte em um estado transitório, de passagem, negando que é o fim da vida. A narrativa de P1 exemplifica as percepçóes de alguns entrevistados, que interpretam a morte como esta passagem:

Pra mim é a passagem de uma vida para outra. A morte pra mim é realmente um descanso pra essa vida (P1).

De acordo com Kovács (1992), a religião sempre buscou entender e explicar de onde vem e para onde vão os homens. A incerteza de saber o que acontece depois da morte faz com que as pessoas procurem respostas espirituais para encontrar um conforto.

De modo geral, este eixo apresentou as diferentes concepçóes dos participantes acerca do tema, mas abordou principalmente o entendimento da morte como parte da vida a partir da experiência vivida com seus pacientes e as crenças religiosas como uma forma de suporte para enfrentar a situação de morte. 


\subsection{A formação profissional e a terminalidade da vida}

O segundo eixo investigado abordou a questão $\mathrm{da}$ morte no processo formativo dos profissionais $\mathrm{da}$ saúde, por ser um fenômeno que incomoda, desafia a autoridade humana e profissional e instiga a luta incessante pela vida. Esta concepção é corroborada pela filosofia adotada nos cursos da área da saúde voltada unicamente para o ensino do cuidado e atençáo à vida e que não prepara o profissional para lidar com a morte. Neste sentido, uma análise dos programas das disciplinas dos cursos de formaçáo dos participantes desta pesquisa mostra o que os autores Brêtas, Oliveira e Yamaguti (2006, p. 478) afirmam: "[...] não existe uma disciplina curricular que trate do assunto de forma não defensiva e biologicista".

Diversos autores, como Lima (2012), Bifulco e Iochida (2009) evidenciam a precariedade da formação dos profissionais de saúde quando se trata da competência para lidar com a morte. Os autores referem que, de modo geral, as universidades náo oferecem nas grades curriculares dos cursos uma disciplina que aborde o tema da morte. Este é abordado de modo muito superficial, relacionado à ética e ao prolongamento de vida. Há pouca preparação para os aspectos a serem enfrentados na realidade prática e não há espaço para discutir os aspectos emocionais, espirituais e sociais que a morte pode trazer para o ser humano.

\subsubsection{A informalidade do ensino sobre a morte}

Para verificar melhor esta questáo, foi realizada uma pesquisa, no site da Universidade Federal de Santa Maria - UFSM, nas grades curriculares dos cursos de formação dos participantes pesquisados a fim de identificar disciplinas que abordassem o tema da morte. Os resultados encontrados mostraram que no curso de Enfermagem, o tema é abordado nas disciplinas: "Psicologia da Saúde", em que há um item da unidade Saúde e doença, que trata da "Doença e morte - a relação profissional/paciente"; "Seminário de integração: identidade profissional da enfermagem", em que o tema não aparece explicitamente no conteúdo programático, mas tem como objetivo

[...] construir, desconstruir e reconstruir conceitos, valores e sentimentos ligados à vida, visando à formação profissional fundamentada nos pressupostos da integralidade [...] (UNIVERSIDADE..., 2010a).
Há também a disciplina "Enfermagem no cuidado ao adulto", que dispóe acerca da relação da família, paciente e equipe no processo de viver, adoecer e morrer. Além destes casos, existem disciplinas abordando questóes de cuidados em situaçôes críticas de vida e relacionadas a procedimentos em urgências e emergências. De alguma forma estáo trabalhando com casos críticos em que o paciente deve ser considerado entre vida e morte, embora não fique clara a abordagem com que essas disciplinas são trabalhadas, se na perspectiva da luta contra a morte e/ou da qualificação da morte.

$\mathrm{Na}$ grade curricular do curso de Medicina, foram encontradas três disciplinas que remetem à morte e ao processo morrer, à ética e ao paciente terminal. Entre elas, a disciplina de "Relação médico-paciente", na qual se observou indícios de que o tema é trabalhado com os alunos, visto que em seu programa são abordadas questôes da relação médico-paciente tanto do ponto de vista do paciente como do médico. Também há uma unidade do programa colocada como "situaçóes especiais", que inclui o paciente terminal. Nesta mesma disciplina há outra unidade destinada a abordar a ética médica no tocante à tomada de decisão. A ementa da disciplina "Urgências e Emergências" aponta para aspectos éticos e médico-legais, abordando o "erro e a falta médica" e a responsabilidade profissional do médico. Por fim, em "Bioética e Deontologia Médica", o programa da disciplina abrange questóes da morte e morrer como a eutanásia, distanásia e suicídio assistido (UNIVERSIDADE..., 2010b). Com isso é possível observar que o curso de Medicina contempla em seu currículo disciplinas que possibilitam a discussão sobre o tema, embora ainda assim náo deixe clara a perspectiva adotada, não parecendo haver um foco relativo aos cuidados paliativos.

No currículo do curso de Terapia Ocupacional da UFSM (UNIVERSIDADE..., 2010c) não consta nenhuma disciplina que apresente em seu programa conteúdos relacionados à morte ou aos cuidados paliativos. Esses temas são abordados de forma incipiente em disciplinas, tais como "Terapia Ocupacional na Saúde da Mulher", "Terapia Ocupacional na Saúde do Idoso", "Intervenção Precoce" e no "Estagio Supervisionado em Terapia Ocupacional", quando este acontece no campo da Oncologia. Essa lacuna já percebida pelo corpo docente será solucionada por meio da reforma curricular prevista.

Sendo assim, no que se refere à estrutura curricular dos cursos investigados parece prevalecer a lógica de que o aluno não precisa ser preparado para enfrentar a morte, muito menos a orientação quanto aos cuidados paliativos. Deste modo, a grande maioria 
dos acadêmicos aprende sozinha sobre o tema ao se expor à situação na vida pessoal e profissional. Portanto, todas as experiências pessoais vividas e o conhecimento adquirido na formação acadêmica passam a ajudá-lo a encontrar respostas adaptativas, quer seja criando uma máscara para usar diante às situaçôes ou enfrentando a questão (LIMA, 2012).

De acordo com Moritz (2005), ao final do curso, na maioria dos casos, o acadêmico defronta-se com os primeiros pacientes e as primeiras mortes, entra em contato com sua própria finitude e ativa um mecanismo de defesa que o leva a fugir de alguma forma e a reproduzir uma postura de frieza. Assim, acredita-se que a maioria dos profissionais irá aprender a encarar a morte quando entrar em contato com ela na prática e ali, por meio do contato direto, criará estratégias de defesa para lidar com a situação.

\subsubsection{Convivência com a morte na formação acadêmica e atuação profissional}

No segundo eixo também foi abordada a realidade vivida pelos participantes da pesquisa, no que se refere à preparação para lidar com a morte durante a formação acadêmica. Conforme os achados, foram encontradas respostas semelhantes em todas as categorias profissionais e acadêmicas pesquisadas. Em vista disso os dados foram apresentados em seu conjunto.

De modo geral os participantes relataram não se sentirem preparados pela formação acadêmica para enfrentar situaçóes de morte, visto que o tema é abordado de forma incipiente e não lhe é atribuída a devida importância. Na maioria das narrativas, o tema aparece quando surge uma situação prática que envolve a questão. Desse modo, a partir da vivência no contexto real da vida acadêmica é disparado o dispositivo para a reflexão sobre a morte e a necessidade do serviço de cuidados paliativos. Ou seja, apenas a experiência prática dará sentido à vivência real da morte no cotidiano do profissional. Os relatos dos participantes investigados também sinalizaram uma elaboração solitária com vistas à compreensão do significado da morte no cotidiano profissional, pois a maioria dos participantes referiu não haver suporte dos docentes nas questóes angustiantes que a morte pode revelar, como pode ser observado nos excertos a seguir:

Com a experiência do dia a dia, que tu vais aprendendo. Ninguém te prepara para uma perda. Preparam a gente para ter qualidade de vida e viver ( $\mathrm{R} 3)$.
Na verdade cada pessoa desenvolve a sua forma de assimilar as coisas. Tu vês o que as outras pessoas fazem [referindo-se a outros profissionais] $e$ forma o teu jeito de fazer (P2).

A gente não tem muito preparo teórico. Mas na prática. É muito pessoal, cada um vai acabar abordando conforme sua personalidade, conforme as experiências que teve. Então, fica algo bem como cada um elabora isso (A2).

$\hat{E}$, você começa a pensar sobre isso, mas acho que só vivencia mesmo numa situação real. A primeira morte é bem traumática, o primeiro atestado de óbito que você preenche, a primeira notícia de morte que você tem que dar, é complicado, né? (R2).

Não é fácil, as primeiras vezes é muito dificill. Não que depois fique fácil de fazer, mas depois tu já aprendes os moldes. Assim, se ela falar isso vou ter que explicar tal coisa'. Tu vais mais preparado para o que vem de volta da família. No começo tu não tens preparação nenhuma (P2).

As narrativas de alguns participantes deixaram claro que é na prática que eles aprenderam a agir e encontraram formas internas de lidar com a questáo. Como estratégia para esta aprendizagem, alguns observaram outros profissionais, outros buscaram leituras e assim foram elaborando formas de abordar $o$ assunto externa e internamente.

Uma prática que pode ser observada em alguns acadêmicos dos cursos pesquisados foi a busca de programas extracurriculares, tais como estágios ou vivências que pudessem trazer novas experiências para serem refletidas. Isso garantiu formações distintas de uns alunos perante outros, além das novas experiências e a possibilidade de pensar e agir diferenciadamente, como pode ser visto nos excertos a seguir:

Não sei se seria bem a formação, mas as experiências que o meu processo de formação me proporcionou me fizeram me aprofundar um pouco mais nesse assunto, porque eu precisei disso (A3).

A gente não chega ao primeiro semestre entrando no hospital, tendo contato com isso e vendo isso [Morte/Cuidados Paliativos]. Pode acontecer quando as pessoas buscam outros estágios em serviços e podem lidar diretamente com isso (A2).

Os dados extraídos das entrevistas confirmaram as impressōes obtidas durante a análise das grades curriculares dos cursos, visto que as respostas às perguntas sobre as disciplinas que abordavam o assunto morte e morrer revelaram que o tema é tratado superficialmente e a morte é colocada como parte do que vão enfrentar, porém não há 
suporte ou estratégias para enfrentamentos reais. Além disso, quando se está em processo formativo, o indivíduo tende a se preocupar mais com suas funçóes principais, relativas ao aprendizado de técnicas e formas de tratamento e manipulação, em detrimento de funçóes essencialmente entendidas como secundárias, evidenciando assim que o ensino é voltado para os procedimentos. Sáo ilustrativos dessa realidade os excertos do acadêmico de Medicina:"Teve uma aula sobre isso [Morte e morrer]. É abordado informalmente, às vezes, numa aula ou outra" (A2), e do acadêmico de Enfermagem:

Eu tive uma aula no $4^{\circ}$ semestre, sobre morte e morrer. Uma aula que realmente a professora conversava com a gente. Mas assim, foi uma aula no $4^{\circ}$ semestre da graduação! Que eu tava aprendendo a puncionar uma veia, que eu tava aprendendo a fazer a sondagem e que eu ainda não tinha a vivência que eu tenho agora e as necessidades que eu tenho agora (A1).

Os resultados da pesquisa indicam que os cursos de graduação pesquisados priorizam os aspectos técnicos da profissão e o acadêmico muitas vezes sente a falta de espaços para abordar suas expectativas e receios diante de suas experiências. Os resultados encontrados são coerentes com os achados de Bifulco e Iochida (2009) quando referem que uma das causas do despreparo dos profissionais para lidar com a morte é que os cursos enfatizam a formaçáo técnico-científica dos alunos para que estes sejam bons profissionais no futuro e, consequentemente, abordam pouco dos aspectos emocionais, espirituais e sociais do ser humano. Nesse sentindo, Esperidião (2003) afirma que, de maneira geral, as necessidades pessoais dos alunos deixam de ser consideradas pelos profissionais formadores e isso pode causar sentimentos de desamparo, solidão ou desespero em situaçóes em que eles sentem necessidade de um suporte emocional para elaborar o que foi vivenciado. A narrativa de A1, é elucidativa:

\section{É um desamparo bem grande, e eu acho que não só com o meu curso, para outros também.}

Além disso, na medida em que não são estimulados a aceitar seus sentimentos e, sim, considerá-los inconvenientes e ameaçadores para seu crescimento profissional, os alunos desaprendem a lidar com as próprias emoçôes, o que pode ter repercussão na sua forma de lidar com as emoçôes dos outros.

Estudos realizados por Bernieri e Hirdes (2007) com acadêmicos do curso de Enfermagem mostram que os alunos precisam de um suporte em suas primeiras vivências com a morte, para que consigam organizar o que sentem e elaborar formas de agir positivas em relação ao assunto. Muitas vezes, ao invés de ser amparado diante da insegurança que permeia a vivência da morte de um paciente, o acadêmico aprende, por meio da observação dos docentes e profissionais com que interage, que se envolver emocional e afetivamente pode prejudicar o raciocínio, o julgamento e as habilidades de agir frente a uma decisão. Assim são levados a reprimir sentimentos, acreditando que poderão atender melhor as pessoas (ESPERIDIÁO, 2003).

Cada profissão precisa exercer seu papel principal, visando seus objetivos. Entretanto, é importante destacar que o paciente é um personagem principal nessa relação e que é essencial que seja visto como um indivíduo e náo apenas como um doente. Para Kübler-Ross (2008), é desafiador focalizar o paciente como pessoa e náo apenas como doente e tratá-lo como ser humano, fazendo-o participar do tratamento.

De um modo geral, as profissóes da saúde estão rompendo com o modelo biomédico e hospitalocêntrico em prol da integralidade das açóes em saúde. Para tanto, cada vez mais são incentivado os trabalhos interdisciplinares e que fujam do enfoque mecanicista. O desafio para formação atualmente é justamente extrapolar o ensino dos cuidados técnicos e procedimentos.

Nesse sentido, Quint Benoliel (1972 apud KOVÁCS, 1992) chama a atenção para a função da Enfermagem na assistência ao paciente, promovendo sua recuperação por meio de intervençóes técnicas permeadas por relaçóes interpessoais. Essas relaçóes se estendem muito além de cuidados técnicos, pois este profissional está mais próximo ao paciente na maior parte do tempo, conhecendo-o melhor. Contudo, a narrativa dos entrevistados revela que, durante a formação do enfermeiro, as questôes ligadas aos sentimentos que a morte pode suscitar não são trabalhadas com a devida consideraçáo que o tema merece, visto que este profissional é aquele que tem o contato mais prolongado e diário com o paciente e a família, vivenciando as tensóes relacionadas à morte durante a rotina hospitalar.

Quanto ao acadêmico da Medicina, Kovács (1992, p. 228) observa que há uma ação generalizada de "dessensibilização de elementos" relacionados à morte que podem afetar a atuação do profissional em cuidados paliativos. Desde o início da formaçáo, o ser humano é tratado de forma fragmentada e o tratamento é direcionado aos seus órgãos ou ossos, sendo objetivada uma finalidade técnico-científica para um controle do corpo e da doença, em que o maior desafio é o controle da morte. Assim, o 
processo de formação do médico tende a imprimir uma visão impessoal e puramente biológica da questão da morte.

Bifulco e Iochida (2009) alertam para o fato de que os profissionais da saúde, principalmente da Medicina, tem a formação voltada para trabalhar com a vida e a cura de doenças e, assim, aumentar a expectativa de vida da população. Os profissionais são preparados para a excelência no controle da cura, promoção da vida e, consequentemente, negação da morte. Náo são preparados para cuidar do processo de morte e morrer, mesmo assim há que se cuidar da vida e também do morrer. Alguns entrevistados revelaram essa prática:

A gente não é formada pra isso. A gente não se permite olhar pra morte (P3).

Como TO [terapeuta ocupacional] a gente tenta focar na qualidade de vida fazer dos últimos momentos 'os melhores da minha vida', não relaciona o sofrimento, a dor, a perda, tenta focar o que ainda posso fazer em vida. Ele [terapeuta ocupacional] vê um lado, trabalha com o ser humano, com o fazer humano, ele não trabalha com o desfazer humano (R3).

Atualmente, com o crescimento da terapia ocupacional no contexto hospitalar e em cuidados paliativos, este tema tem se tornado muito importante para essa categoria profissional. Considerando que a morte é inerente à vida e faz parte do cotidiano do ser humano, o terapeuta ocupacional é um profissional convocado a participar desta atuação.

Diante desta presença e magnitude do tema no cotidiano dos indivíduos, a morte deveria merecer destaque na formação acadêmica, até porque ela não está restrita ao contexto hospitalar. O entrevistado P3 deixou claro essa realidade:

Nossa formação não nos permite espaço para que a gente converse efetivamente sobre a morte a fim de que a gente aprofunde os estudos e compreenda a morte no cotidiano. Uma vez que a gente sabe que a TO se ocupa do cotidiano dos sujeitos e a morte é algo que está instaurada ali, a gente não se permite parar e estudar e refletir sobre a morte. Então a gente negligencia, afasta ela dos nossos olhos de modo que a gente náo precise conviver com ela (P3).

Considerando o conceito de cotidiano como "[...] o lugar onde buscamos exercer nossa atividade prática transformadora, é o social, o contexto em que vivemos [...]" (FRANCISCO, 2008, p. 76), o cotidiano é onde a vida ocorre e consequentemente é também onde se convive com a morte e seu impacto.
Assim, as perdas, separaçóes, luto e morte, fazem parte do cotidiano do homem, fazendo da morte um tema vivido frequentemente, mas que vem mascarado por outras palavras (KOVÁCS, 1992).

$\mathrm{O}$ adoecimento causa uma ruptura brusca no cotidiano e está associado ao sofrimento físico e emocional que necessitam de adaptaçáo a um novo processo de viver, que muitas vezes não ocorre facilmente (ROCHA; MELLO, 2004). O terapeuta ocupacional é o profissional mais indicado para trabalhar com o cotidiano interrompido, tendo em vista seu objeto de estudo e intervenção, a ação humana que se traduz como o fazer significativo do homem na sua vida de relaçôes e atividades significativas de sua vida diária. O paciente em terminalidade da vida merece o respeito e a consideraçáo de ter esse momento ressignificado e qualificado. Para tanto é imprescindível reorganizar junto a ele o seu cotidiano, para que viva em plenitude e ativamente até quando for possível. Por meio de atividades e diálogos fundamentais, o profissional auxilia o paciente a desmistificar este momento socialmente visto como negativo e traumático (FERRER; SANTOS, 2007).

A terapia ocupacional nos cuidados paliativos atua com a díade paciente/cuidador contribuindo para o manejo das dificuldades referidas e observadas, com vistas à promoção do máximo grau de independência e/ou autonomia no desempenho ocupacional em prol de maior qualidade de vida, conforto e dignidade no hospital ou domicílio, em detrimento das perdas funcionais, cognitivas, sociais e emocionais (QUEIROZ, 2012).

Neste sentido, embora pequena, há uma crescente contribuição de terapeutas ocupacionais brasileiros atuando e pesquisando sobre o tema, como Queiroz (2012), Amoroso, Junqueira e Mastropietro (2006), Othero e Costa (2007), Seki e Galheigo (2010), De Carlo et al. (2005), Takeda (2009), De Carlo e Queiroz (2007), entre outros.

Diante das exigências para o bom desempenho de seu papel profissional, o terapeuta ocupacional, o médico e o enfermeiro necessitam de uma formação adequada, humanizada e qualificada para que aprendam a trabalhar com a morte. Esperidião (2003) destaca a importância de viabilizar a humanização da assistência a partir da humanizaçáo do ensino, por meio das experiências adquiridas ainda na graduação, o estudo centrado no aluno e não apenas na técnica a ser ensinada. Seguindo esse raciocínio, Bifulco e Iochida (2009, p. 98) consideram: 
A educação para lidar com a morte deveria ser um dos objetivos desses cursos, devendo ser entendida como um vasto campo de conhecimento que compreende o significado da morte, os processos de morrer, o pesar do luto, e envolve intencionalidade e planejamento, da mesma forma que outras disciplinas ou programas de saúde.

Enfim, Branco (2003) propóe que se desenvolvam estratégias que façam os acadêmicos associarem a competência técnica ao ato de cuidar além da teoria, que haja discussão sobre os problemas que os alunos enfrentam e que, principalmente, se mostre como isso é importante para a formação deles como profissionais realmente competentes para atuar com o sujeito e não com a doença.

\section{Conclusão}

A morte é um tema que causa muito desconforto para a maioria das pessoas, muitas pesquisas tentaram desvendar o sentimento do homem perante a morte, sendo que a maioria recaiu sobre a ideia de que a morte é um fenômeno biológico que a sociedade, de modo geral, náo interpreta como algo que deveria fazer parte do ciclo vital. É uma visão social constituída que instiga as pessoas a rejeitá-la como parte desse ciclo. Nega-se a morte dizendo que não se sabe conviver com a ideia ou que não se quer refletir sobre o assunto. As pessoas são despreparadas pela vida para falar sobre o tema com naturalidade, principalmente quando se trata da própria finitude.

Com o avanço das tecnologias, surgiram muitos meios de buscar a cura e controlar a morte. Isso manifesta ainda mais o sentimento de negação da morte que existe na maioria da população. A tecnologia ajuda a prolongar a vida dos doentes, porém náo os ajuda a vivenciar com qualidade o processo de morrer nos últimos dias de sua vida. Os profissionais da saúde que estáo frequentemente no contato com a morte possuem diferentes visóes e formas de lidar com o tema.

Os dados analisados nesta pesquisa trouxeram como primeira constatação a noção de singularidade, em que cada indivíduo elabora e constrói as suas concepçóes sobre a morte a partir das suas experiências, tanto pessoais como profissionais e partem deste processo de elaboração para adotar as estratégias com que olham e (re)agem perante a situação.

De modo geral, os participantes expressaram o entendimento da morte, considerando-a como um processo fisiológico inerente à vida ou pela compreensão espiritualizada da existência humana. São esses os pilares que os auxiliam e dão suporte para enfrentar a situaçáo de morte no cotidiano do seu fazer profissional.

No tocante ao processo formativo, tanto na investigação das matrizes curriculares dos cursos quanto por meio das entrevistas, a pesquisa revelou que os cursos investigados ainda oferecem uma formação tecnicista baseada na perspectiva biomédica, pouco centrada na humanização da assistência e nos cuidados paliativos. Há pouco preparo do acadêmico da saúde para trabalhar as situações de perda, morte e luto. É possível inferir que há certo conforto em relaçáo aos conhecimentos construídos relativos às técnicas e procedimentos terapêuticos, porém há um sentimento de solidão em relação à criação de estratégias para lidar com a finitude de seus pacientes. Muitos não buscam amparo em colegas nem nos professores. O suporte emocional muitas vezes é encontrado fora da universidade, junto aos familiares, amigos ou ajuda profissional. Há uma espécie de desamparo para lidar com as próprias reaçóes e despreparo para lidar com a situaçáo que também pode ser estendida ao trato da questão no que concerne ao apoio e conforto ao paciente e à família.

Entretanto, a partir dos dados obtidos é possível propor à comunidade acadêmica dos cursos investigados (e dos da área da saúde de um modo geral) uma reflexão sobre o processo formativo, a implantação das políticas de humanização da atenção à saúde, a transição do modelo biomédico para a integralidade do cuidado à saúde de forma interdisciplinar e intersetorial e, nesse contexto, a implantação dos princípios dos cuidados paliativos nas açōes em saúde.

Uma sugestão para o serviço da unidade pesquisada, que ainda náo aderiu aos cuidados paliativos integralmente, é que além da formação inicial e continuada, também seja disponibilizado nos serviços um ambiente acolhedor, reflexivo e com agenda para reuniōes da equipe multiprofissional para que, a partir da realidade e dos profissionais dos serviços, se encontrem estratégias para elaboração pessoal e de atençáo qualificada ao paciente que requer maior atenção.

É possível que medidas como estas possam contribuir para a formaçáo de um profissional habilitado e preparado física e psicologicamente para conviver com a morte e ser capaz de compreender o processo de morte e morrer e seu significado para o paciente e sua família, tornando-se competente para ajudá-los a vivenciar uma morte digna. 


\section{Referências}

AMOROSO, C. S.; JUNQUEIRA, T.; MASTROPIETRO, A. P. A terapia ocupacional junto à pacientes em estado de terminalidade. 2006. 90 f. Monografia (Graduação em Terapia Ocupacional) - Centro Universitário Claretiano, Batatais, 2006.

ARAÚJO, P. V. R. Percep̧̧ão de crianças sobre a morte e morrer: estudo em uma unidade de oncologia. São Cristovão: Editora UFS, 2006.

BERNIERI, J.; HIRDES, A. O preparo dos acadêmicos de enfermagem brasileiros para vivenciarem o processo morte-morrer. Texto \& Contexto - Enfermagem, Florianópolis, v. 16, n. 1, p. 89-96, 2007.

BIFULCO, V. A.; IOCHIDA, L. C. A formação na graduação dos profissionais de saúde e a educação para o cuidado de pacientes fora de recursos terapêuticos de cura. Revista Brasileira Educação Médica, São Paulo, v. 33, n. 1, p. 92-100, 2009.

BRANCO, R. F. G. R. Aspectos históricos do ensino da relação médico-paciente. In: BRANCO, R. F. G. R. A relação com o paciente: teoria, ensino e prática. Rio de Janeiro: Guanabara Koogan, 2003. p. 97-104.

BRASIL. Conselho Nacional de Saúde. Resoluçấo no 466, de 12 de dezembro de 2012. Institui as normas regulamentadoras para de pesquisas realizadas envolvendo seres humanos. Diário Oficial [da] República Federativa do Brasil, Poder Executivo, Brasília, DF, 12 dez. 2012.

BRÊTAS, J. R. S.; OLIVEIRA, J. R.; YAMAGUTI, L. Reflexôes de estudantes de enfermagem sobre morte e o morrer. Revista Escola Enfermagem, São Paulo, v. 40, n. 4, p. 477-483, 2006.

CONNELLY, F. M.; CLANDININ, D. J. Relatos de experiencia e investigación narrativa. In: LARROSA, J. et al. Déjame que te cuente. Barcelona: Alertes, 1995. p. 11-59.

COSTA, J. C.; LIMA, R. A. G. Luto da equipe: revelaçóes dos profissionais de enfermagem sobre o cuidado à Criança/adolescente no processo de morte e morrer. Revista Latino-Americana Enfermagem, Ribeirāo Preto, v. 13, n. 2, p. 151-157, 2005.

DE CARLO, M. P. et al. Terapia Ocupacional em dor e dos Cuidados Paliativos - constituiçấo do campo e formação profissional. Revista Dor, São Paulo, v. 5, n. 2, p. 560-566, 2005.

DE CARLO, M. P.; QUEIROZ, M. E. Dor e Cuidados Paliativos: Terapia Ocupacional e Interdisciplinaridade. São Paulo: Roca, 2007.

ESPERIDIÃO, E. A relaçấo professor-aluno e a construção da relaçấo com o paciente. In: BRANCO, R. F. G. R. A relação com o paciente: teoria, ensino e prática. Rio de janeiro: Guanabara Koogan, 2003. p. 97-104.

FERRER, A. L.; SANTOS, W. A. Terapia Ocupacional na atenção a pacientes com dor oncológica em Cuidados
Paliativos. In: DE CARLO, M. P.; QUEIROZ, M. E. Dor e Cuidados Paliativos: Terapia Ocupacional e Interdisciplinaridade. São Paulo: Roca, 2007. p. 147-166.

FRANCISCO, B. R. Terapia ocupacional. Campinas: Papirus, 2008.

GIL, A. C. Como elaborar projetos de pesquisa. São Paulo: Editora Atlas, 2010.

KOVÁCS, M. J. A morte e o morrer em oncologia. In: CEREZETTI, C. R. N.; VEIT, M. T.; FELÍCIO, J. L. Psicologia nas organizaçóes de saúde: da prevenção ao tratamento. São Paulo: Centro Universitário São Camilo, 2010. p. 143-160.

KOVÁCS, M. J. Morte e desenvolvimento humano. São Paulo: Casa do Psicólogo, 1992.

KÜBLER-ROSS, E. Sobre a Morte e o Morrer. São Paulo: WMF Martins Fontes, 2008.

LIMA, J. L. Morte e morrer: a importância do estudo da morte para profissionais de enfermagem. Niterói: UFF, 2012. Disponível em: <http://www.professores.uff.br/ jorge/morte.pdf>. Acesso em: 05 out. 2012.

MACIEL, M. G. S. et al. Critérios de qualidade para os cuidados paliativos no Brasil. Documento elaborado pela Academia Nacional de Cuidados Paliativos. Rio de Janeiro: Diagraphic, 2006.

MORAES, R.; GALIAZZI, M. C. Analise textual discursiva. Ijuí: Unijuí, 2007.

MORITZ, R. D. Os profissionais de saúde diante da morte e do morrer. Bioética, Brasília, v. 13, n. 2, p. 5163, 2005.

MORITZ, R. D.; NASSAR, S. M. A Atitude dos Profissionais de Saúde Diante da Morte. Revista Brasileira Terapia Intensiva, São Paulo, v. 16, n. 1, p. 14-21, 2004.

OTHERO, M. B.; COSTA, D. G. Propostas desenvolvidas em Cuidados Paliativos em um hospital amparador - Terapia Ocupacional e Psicologia. Pratica Hospitalar, São Paulo, v. 9, n. 52, p. 157-60, 2007.

QUEIROZ, M. E. G. Q. Atenção em Cuidados Paliativos. Cadernos de Terapia Ocupacional da UFSCar, Sáo Carlos, v. 20, n. 2, p. 203-205, 2012.

ROCHA, E. F.; MELLO, M. A. F. Os sentidos do corpo e da intervençáo hospitalar. In: DE CARLO, M. R. P.; LUZO, M. C. M. Terapia Ocupacional: reabilitação física e contextos hospitalares. São Paulo: Roca, 2004. p. 29-46.

RODRIGUES, J. C. Tabu da morte. Rio de Janeiro: FIOCRUZ, 2006.

SEKI, N. H.; GALHEIGO, S. M. O uso da música nos Cuidados Paliativos: humanizando o cuidado e facilitando o adeus. Interface - Comunicação, Saúde, Educação, Botucatu, v. 14, n. 33, p. 273-284, 2010. 
SILVA, K. C. O. et al. O "não" à morte oferece o "sim" à obstinação terapêutica? Revista de Enfermagem, Santa Maria, v. 2, n. 2, p. 442-448, 2012.

TAKEDA, N. Terapia ocupacional modulando a dor em pacientes oncológicos sob Cuidados Paliativos. 2009. $87 \mathrm{f}$. Dissertação (Mestrado em Biotecnologia Médica) - Universidade Estadual Paulista, Botucatu, 2009.

TORRES, W. C. O conceito da morte na criança. Arquivos Brasileiros de Psicologia, Rio de Janeiro, v. 31, n. 4, p. 9-34, 1979.

UNIVERSIDADE FEDERAL DE SANTA MARIA

- UFSM. Ementário do Curso de Enfermagem. Santa
Maria, 2010a. Disponível em: <http://portal.ufsm.br/ ementario/curso.html?curso=762>. Acesso em: 15 maio 2013.

UNIVERSIDADE FEDERAL DE SANTA MARIA UFSM. Ementário do Curso de Medicina. Santa Maria, 2010b. Disponível em: <http://w3.ufsm.br/prograd/ cursos>. Acesso em: 15 maio 2013.

UNIVERSIDADE FEDERAL DE SANTA MARIA UFSM. Ementário do Curso de Terapia Ocupacional. Santa Maria, 2010c. Disponível em: <http://portal.ufsm.br/ementario/curso.html?curso=1251>. Acesso em: 15 maio 2013.

\section{Contribuição das Autores}

Aline Viegas Sartori foi responsável pelo desenvolvimento da pesquisa, concepção e revisão do artigo. Amara Lúcia Holanda Tavares Battistel foi orientadora desta pesquisa com contribuições no desenvolvimento, concepção e revisão do artigo. Ambas autoras contribuíram igualmente para a concepção e redação do texto. Todos os autores aprovaram a versão final do texto.

\section{Notas}

${ }^{1}$ O estudo foi aprovado pelo Comitê de Ética em Pesquisa (CAAE 13053213.8.0000.5346) e obedeceu aos preceitos éticos conforme Resolução 466/12 (BRASIL, 2012).

${ }^{2}$ Projeto CAACTO: Cuidado e Atenção ao Adolescente e à Criança em Tratamento Oncológico. Projeto de Pesquisa e Extensão vinculado ao Curso de Terapia Ocupacional da Universidade Federal de Santa Maria/RS.

${ }^{3} \mathrm{O}$ impacto da morte no cotidiano dos profissionais e acadêmicos das áreas da Enfermagem, Medicina e Terapia Ocupacional que atuam no Centro de Tratamento da Criança e do Adolescente com Câncer (CTCriac) do Hospital Universitário de Santa Maria (HUSM), trabalho de Conclusão de Curso apresentado ao curso de Terapia Ocupacional/UFSM. 